\title{
Metabolic effects of diets differing in glycaemic index depend on age and endogenous glucose-dependent insulinotrophic polypeptide in mice
}

\author{
F. Isken • M. O. Weickert • M. H. Tschöp • \\ R. Nogueiras • M. Möhlig • A. Abdelrahman • S. Klaus • \\ B. Thorens $\cdot$ A. F. Pfeiffer
}

Received: 6 June 2009/Accepted: 24 June 2009 /Published online: 31 July 2009

(C) Springer-Verlag 2009

\begin{abstract}
Aims/hypothesis High- vs low-glycaemic index (GI) diets unfavourably affect body fat mass and metabolic markers in rodents. Different effects of these diets could be agedependent, as well as mediated, in part, by carbohydrateinduced stimulation of glucose-dependent insulinotrophic polypeptide (GIP) signalling.

Methods Young-adult (16 weeks) and aged (44 weeks) male wild-type (C57BL/6J) and GIP-receptor knockout $\left(\mathrm{Gipr}^{-1-}\right)$ mice were exposed to otherwise identical highcarbohydrate diets differing only in GI (20-26 weeks of intervention, $n=8-10$ per group). Diet-induced changes in body fat distribution, liver fat, locomotor activity, markers of insulin sensitivity and substrate oxidation were investigated, as well as changes in the gene expression of anorexigenic and orexigenic hypothalamic factors related to food intake.
\end{abstract}

\footnotetext{
F. Isken $\cdot$ M. O. Weickert $(\bowtie) \cdot$ M. Möhlig $\cdot$ A. Abdelrahman •

A. F. Pfeiffer

Department of Clinical Nutrition,

German Institute of Human Nutrition,

Arthur-Scheunert Allee 155,

14558 Potsdam-Rehbruecke, Germany

e-mail: martin.weickert@uhcw.nhs.uk

F. Isken • M. O. Weickert • M. Möhlig • A. F. Pfeiffer

Department of Endocrinology, Diabetes and Nutrition,

Charité-University-Medicine,

Campus Benjamin Franklin,

Berlin, Germany

M. O. Weickert

Warwickshire Institute for the Study of Diabetes,

Endocrinology and Metabolism,

University Hospitals of Coventry and Warwickshire,

Coventry, UK
}

Results Body weight significantly increased in young-adult high- vs low-GI fed mice (two-way ANOVA, $p<0.001$ ), regardless of the Gipr genotype. The high-GI diet in youngadult mice also led to significantly increased fat mass and changes in metabolic markers that indicate reduced insulin sensitivity. Even though body fat mass also slightly increased in high- vs low-GI fed aged wild-type mice $(p<0.05)$, there were no significant changes in body weight and estimated insulin sensitivity in these animals. However, aged $\mathrm{Gipr}^{-/}$ vs wild-type mice on high-GI diet showed significantly lower cumulative net energy intake, increased locomotor activity and improved markers of insulin sensitivity.

Conclusions/interpretation The metabolic benefits of a low-GI diet appear to be more pronounced in younger animals, regardless of the Gipr genotype. Inactivation of GIP signalling in aged animals on a high-GI diet, however, could be beneficial.

\footnotetext{
M. H. Tschöp

Department of Psychiatry,

University of Cincinnati Genome Research Institute,

Cincinnati, OH, USA

R. Nogueiras

Department of Physiology,

University of Santiago de Compostela,

Santiago de Compostela, Spain

S. Klaus

Department of Pharmacology,

German Institute of Human Nutrition Potsdam-Rehbruecke,

Nuthetal, Germany

B. Thorens

Department of Physiology and Center for Integrative Genomics,

University of Lausanne,

Lausanne, Switzerland
} 
Keywords Ageing · Body fat mass - GIP receptor knockout · Glycaemic index · Hypothalamic satiety factors · Insulin resistance $\cdot$ Locomotor activity

$\begin{array}{ll}\text { Abbreviations } \\ \text { GI } & \text { Glycaemic index } \\ \text { GIP } & \text { Glucose-dependent insulinotrophic polypeptide } \\ \text { GIPR } & \text { GIP receptor } \\ \text { GTT } & \text { Glucose tolerance test }\end{array}$

\section{Introduction}

High- vs low-glycaemic index (GI) diets significantly increase body fat mass and insulin resistance in rodents $[1,2]$. In humans, however, beneficial effects of low-GI diets have not been consistently shown [3-7], partly explained by the known problem of controlling confounding factors such as fibre intake and the lack of suitable control groups [8]. Furthermore, in the majority of observational studies that reported associations of GI with risk of type 2 diabetes and cardiovascular disease, participants were relatively young [3, 9-11]. However, metabolic responses to nutritional challenges might differ, depending on age. Indeed, the only available long-term prospective cohort study investigating potential effects of diets differing in GI in aged participants (mean age 71 years) showed no associations of the GI with both metabolic markers and risk of CHD [12]. Notably, also in rodents, the reported beneficial effects of low- vs high-GI diets are exclusively derived from studies exposing young animals [1, 13-18] or, in the only available long-term study, beginning the dietary intervention at a young age [2].

Effects of diets differing in GI could be further mediated, in part, by carbohydrate-induced stimulation of glucosedependent insulinotrophic polypeptide (GIP) signalling. GIP is released following fat or carbohydrate consumption and modulates insulin secretion, as well as fat metabolism [19] and locomotor activity [20]. We have recently shown that deficiency of the GIP receptor (GIPR) also affects cumulative food intake, at least in an oestrogen-deficient state [21]. Consumption of low-GI soluble dietary fibre reduces circulating GIP in diabetic humans [22], probably because of delayed carbohydrate absorption. Furthermore, distinct age-associated changes in body composition and insulin resistance in Gipr knockout $\left(\mathrm{Gipr}^{-/-}\right)$vs wild-type mice fed a normal diet have been recently reported [23].

Therefore, both the age and the Gipr genotype could influence effects of high- vs low-GI diets on body composition and metabolic markers. To test these hypotheses, we performed a 20-26 week dietary intervention study exposing young-adult (16 weeks) vs aged (44 weeks) male wild-type (C57BL/6J) and $\mathrm{Gipr}^{-/-}$mice to otherwise identical high-carbohydrate diets, differing only in GI. Effects of the diets on body composition and markers of insulin sensitivity and substrate oxidation were investigated in all groups of mice. Locomotor activity and expression of hypothalamic factors involved in the regulation of food intake were additionally investigated in aged animals.

\section{Methods}

Animals The protocol for all animal experiments was approved by the local governmental animal ethic review board (Brandenburg, Germany). The animals were kept in accordance with the National Institutes of Health guidelines for care and use of laboratory animals. Animals were housed individually at a temperature of $22^{\circ} \mathrm{C}$ with a $12 \mathrm{~h}$ light-dark cycle in cages with soft wood bedding. The generation of $\mathrm{Gipr}^{-1-}$ mice on the C57BL/6 background used in these experiments has been previously described [24].

In the first experiment, 16-week-old male $\mathrm{Gipr}^{-1-}$ and control (wild-type) mice were allocated to four groups ( $n=$ 10 per group) and were fed high- vs low-GI diets for 20 weeks, with unlimited access to liquids and experimental diets (Table 1). Diets were isoenergetic and only differed in starch composition/absorption rate and, as such, the GI, as detailed below.

In the second experiment, 44-week-old animals were exposed to a similar protocol ( $n=8$ mice per group). However, because after 20 weeks of dietary intervention no significant differences in body weight were seen in aged mice, the dietary intervention in these animals was extended for a further 6 weeks, resulting in a 26 week dietary intervention period.

After the experimental period animals were killed in a fed state. Organs were isolated after rapid preparation. Hypothalamic tissue was submerged in liquid nitrogen and immediately stored at $-80^{\circ} \mathrm{C}$ until RNA preparation.

Characterisation of experimental diets Prior to the main experiments, postprandial glucose and insulin responses to the here-used experimental high- $(100 \%$ amylopectin, $0 \%$ amylose) vs low- (30\% amylopectin, $70 \%$ amylose) GI diets were tested in a separate group of male C57BL/6J mice $(n=16)$. In order to achieve comparable food intake with both diets, eight mice per group were trained for 5 days. Animals consumed a small portion of standard chow, by introducing a $1 \mathrm{~g}$ pellet (Altromin 1324 Fortified; Altromin, Lage, Germany) into the cage of individually housed mice at 08:00 hours, following an overnight fast. After 10 min the leftover pellets were removed. During the training period, mice were given free access to standard 
Table 1 Macronutrient composition of the experimental diets

\begin{tabular}{|c|c|c|}
\hline Composition & High-GI diet & Low-GI diet \\
\hline \multicolumn{3}{|l|}{ Diet composition $(\mathrm{g} / \mathrm{kg})$} \\
\hline Casein $^{\mathrm{a}}$ & 200 & 200 \\
\hline Starch $^{\mathrm{b}} 1$ (100\% amylopectin) & 542 & - \\
\hline $\begin{array}{l}\text { Starch }^{\mathrm{b}} 2(70 \% \text { amylose, } 30 \% \\
\text { amylopectin) }\end{array}$ & - & 542 \\
\hline Sucrose $^{c}$ & 85 & 85 \\
\hline Gelatine $^{\mathrm{d}}$ & 20 & 20 \\
\hline Soybean oil ${ }^{\mathrm{e}}$ & 50 & 50 \\
\hline Wheat bran ${ }^{\mathrm{f}}$ & 33 & 33 \\
\hline Mineral mixture ${ }^{\mathrm{g}}$ & 50 & 50 \\
\hline Vitamin mixture $^{\mathrm{h}}$ & 20 & 20 \\
\hline \multicolumn{3}{|l|}{ Macronutrient, metabolisable energy (\%) } \\
\hline Protein & 23 & 23 \\
\hline Carbohydrates & 65 & 65 \\
\hline Fats & 12 & 12 \\
\hline Measured diet energy content $(\mathrm{kJ} / \mathrm{g})$ & 17.4 & 17.5 \\
\hline
\end{tabular}

${ }^{a}$ Dauermilchwerk Peiting, Landshut, Germany

${ }^{\mathrm{b}}$ National Starch and Chemical, Hamburg, Germany

${ }^{\mathrm{c}}$ EUCO, Hamburg, Germany

${ }^{\mathrm{d}}$ Gelita Deutschland, Eberbach, Germany

${ }^{\mathrm{e}}$ Vandemoortele Deutschland, Dresden, Germany

${ }^{\mathrm{f}}$ SchapfenMühle, Ulm, Germany

${ }^{\mathrm{g}}$ Mineral mix per $100 \mathrm{~g}$ diet: Ca, $930 \mathrm{mg}$; P, $730 \mathrm{mg}$; Mg, $80 \mathrm{mg}$; Na, 440 mg; K, 710 mg; S, 170 mg; Cl, 360 mg; Fe, 20 mg; Mn, 10 mg; $\mathrm{Zn}, 3 \mathrm{mg} ; \mathrm{Cu}, 800 \mathrm{mg}$; I, $40 \mathrm{mg}$; F, $400 \mathrm{mg}$; Se, $20 \mathrm{mg}$; Co, $10 \mathrm{mg}$ (Altromin)

${ }^{\mathrm{h}}$ Vitamin mix containing $17.5 \mathrm{~g} / 100 \mathrm{~g}$ DL-methionine; vitamin content in $100 \mathrm{~g}$ diet: $\mathrm{A}, 0.45 \mathrm{mg} ; \mathrm{D}_{3}, 1.3 \mathrm{mg} ; \mathrm{K}_{3}, 1 \mathrm{mg}$; $\mathrm{B}_{1}, 2 \mathrm{mg} ; \mathrm{B}_{2}, 2 \mathrm{mg}$; $\mathrm{B}_{6}, 1.5 \mathrm{mg} ; \mathrm{B}_{12}, 3 \mathrm{mg}$; niacin, $5 \mathrm{mg}$; pantothenate, $5 \mathrm{mg}$; folic acid, $1 \mathrm{mg}$; biotin, $20 \mathrm{mg}$; choline chloride, $100 \mathrm{mg}$; $p$-aminobenzoic acid, $10 \mathrm{mg}$; inositol, $10 \mathrm{mg}$; E, $16.4 \mathrm{mg}$ (Altromin)

chow from 11:00 hours to 20:00 hours. On day 5, animals received $500 \mathrm{mg}$ of experimental diets differing only in starch composition. Blood samples from the tail vein (0 $\mathrm{min})$ for measurement of plasma glucose and insulin levels were drawn in the overnight-fasted state. Further blood samples were drawn only from mice that consumed the whole portion of the test meals within $5 \min (30,60,90$ and $120 \mathrm{~min}$ ). Metabolisable macronutrients of the diets were calculated according to the energy contents of casein $(15.7 \mathrm{~kJ} / \mathrm{g})$, carbohydrates $(16 \mathrm{~kJ} / \mathrm{g})$ and fat $(38 \mathrm{~kJ} / \mathrm{g})$. The macronutrient composition of the diets is shown in Table 1 .

Digestibility of the diets and cumulative energy intake Faecal samples of animals were collected over 1 week during the third month of dietary intervention. Food intake was recorded for further analysis of energy balance. After drying, the energy content of diet samples and faeces was determined by bomb calorimetry (IKA C5003; IKA Werke,
Staufen, Germany). Digested energy, defined as (diet energy intake $[\mathrm{kJ} / \mathrm{g}])$ - (energy loss via the faeces $[\mathrm{kJ} / \mathrm{g}]$ ) was calculated for all groups of mice. Digestibility of the diet (expressed in per cent) was defined as ([digested energy $\{\mathrm{kJ} / \mathrm{g}\}] /[$ diet energy intake $\{\mathrm{kJ} / \mathrm{g}\}]) \times 100$. Cumulative digested energy was calculated over an experimental period of 18 weeks in young-adult animals and over 22 weeks in aged animals, by multiplying the respective measured diet energy intakes with digestibility, which was measured over 1 week.

Body composition Body composition (fat mass, lean mass and free fluids) was measured every $2-4$ weeks using nuclear magnetic resonance spectroscopy (Mini Spect MQ 10 NMR Analyser; Bruker, Karlsruhe, Germany). Body weight was recorded every week.

Analysis of hepatic triacylglycerols Frozen liver tissue was ground in liquid nitrogen to a homogenous powder. One hundred milligrams of tissue was homogenised in $5 \mathrm{ml}$ of $10 \mathrm{mmol} / \mathrm{l}$ sodium phosphate buffer containing $1 \mathrm{mmol} /$ 1 EDTA and $1 \%$ solution (wt/vol.) polyoxyethylene 10 tridecyl ether, using an Ultra-Turrax (IKA Werke). Samples were centrifuged $(10 \mathrm{~min}, 20,000 \mathrm{~g})$ and the supernatant fraction was incubated at $70^{\circ} \mathrm{C}$ for $5 \mathrm{~min}$. Triacylglycerols (Triglyceride Reagent; Sigma, St Louis, MO, USA) and protein (DC protein assay; Bio-Rad, Hercules, CA, USA) levels were analysed in triplicate. Because of potential degeneration processes caused by different storage times until measurement in young and aged groups results were normalised to a wild-type group on high-GI diet in both experiments.

Response to i.p. insulin injection (insulin tolerance test) Insulin sensitivity was estimated in the fed state after 17 weeks of dietary intervention in both young-adult and aged animals, using i.p. injection of insulin $(0.75 \mathrm{IU} / \mathrm{kg}$ body mass; Actrapid, Novo Nordisk), as described previously [25].

Glucose tolerance test (GTT) GTTs were performed at week 15 in young-adult mice and at week 20 in aged mice by i.p. glucose injection after an overnight fast, as detailed previously [25]. Because no significant difference in body weight after 20 weeks of high- vs low-GI diets in aged mice was observed, we (1) extended the intervention period in aged mice by a further 6 weeks, and (2) used a smaller dose of glucose injection $(1 \mathrm{~g} / \mathrm{kg}$ body weight instead of $2 \mathrm{~g} / \mathrm{kg}$ body weight) in aged vs young-adult animals in order to further increase the sensitivity of the GTT.

Indirect calorimetry Oxygen consumption $\left(\dot{V}_{2}\right)$ and $\mathrm{CO}_{2}$ production $\left(\dot{V} \mathrm{CO}_{2}\right)$ were assessed by indirect calorimetry in individual mice, using an open respirometric system gas 
analyser (Magnos 16 and Uras 14; Hartmann \& Braun, Frankfurt, Germany). Mice were unrestrained and had free access to their respective high- vs low-GI diets. $V \mathrm{O}_{2}$ and $\dot{V} \mathrm{CO}_{2}$ were determined every $6 \mathrm{~min}$ over a $22 \mathrm{~h}$ period. The RQ was calculated by dividing $\dot{V} \mathrm{CO}_{2}$ by $\dot{V} \mathrm{O}_{2}$. Recorded energy expenditure was normalised for metabolic body weight (body weight $\left[\mathrm{kg}^{0.75}\right]$ ). RQ measurements were performed after 12 weeks of dietary intervention in young-adult mice and after 20 weeks of dietary intervention in aged mice.

Spontaneous locomotor activity analysis Mouse locomotor activity within the home cage environment was measured in aged mice, using an infrared light system (TSE; Bad Homburg, Germany). The sensors registered the activity of the animal by sensing the body heat image and its spatial displacement over time. Activity was recorded at week 25 over $24 \mathrm{~h}$, after 2 days of adaptation, and was expressed as counts per hour.

$R N A$ extraction and real-time $R T-P C R$ Total RNA was extracted from total hypothalamus of animals in a nonfasted state with an RNeasy lipid tissue kit (QIAgen, Hilden, Germany). Mouse hypothalamic expression of the mRNA encoding genes for neuropeptide Y (Npy), agoutirelated peptide (Agrp), cocaine and amphetamine-related transcript (Cart [also known as Cartpt]) and proopiomelanocortin (Pomc) were measured using a Biosystems 7300 real-time RT-PCR system (Foster City, CA, USA) as described previously [21]. Cycle threshold values from each experimental sample were used calculating the respective gene and $18 \mathrm{~S}$ mRNA as compared with the standard. The oligonucleotide specific primers were: $18 \mathrm{~S}$ : forward 5'-CGGCTACCACATCCAAGGAA-3'; reverse 5'-GCTGGAATTACCGCGGCT-3'; probe 5'-GACGG CAAGTCTGGTGCCAGCA-3'; Npy: forward 5'-ACA GAAAACGCCCCCAGAAC-3'; reverse 5'-CGGGAGAA CAAGTTTCATTTCC-3'; probe 5'-AGGCTTGAA GACCCTTCCATGTGGTGAT-3'; Agrp: forward 5'ACAACTGCAGACCGAGCAGAA-3'; reverse 5'CGACGCGGAGAACGAGACT-3'; probe 5'-CAGAAGG CAGAAGCTTTGGCGGAGGT-3'; Cart: forward 5'CGCATTCCGATCTACGAGAAGAA-3'; reverse 5'CCTGGCCCCTTTCCTCACT-3'; probe 5'-CCAAG TCCCCATGTGTGACGCTGGAG-3'; Pomc: forward 5'GAGAGGCCACTGAACATCTTTGTC-3'; reverse 5'TGCAGAGGCAAACAAGATTGG-3'; probe 5'-AGA GAGCTGCCTTTCCGCGACAGG-3'

Statistical analysis Quantitative data are presented as means \pm SE. Data were analysed using two-way ANOVA to detect influences of the diet and the genotype, and the combined effect of diet and genotype (diet $\times$ genotype). A two-tailed Student's $t$ test for unpaired samples was used for subgroup analyses. Time course longitudinal changes of body weight were analysed using repeated-measured ANOVA with body weight at specific time points given as within-animal factors, and the diet and the genotype given as between-animal factors. AUC calculation was performed by the trapezoidal method. The insulin resistance index was estimated by homeostasis model assessment of insulin resistance (HOMA-IR) using the formula [(fasting glucose $(\mathrm{mmol} / \mathrm{l})) \times($ fasting insulin $(\mathrm{pmol} / \mathrm{l}) \times 7.175) / 22.5)]$. All data were assessed using SPSS 14 (Chicago, IL, USA). A $p<0.05$ was considered significant.

\section{Results}

GI of the test meals After the training period, six of eight animals in each group consumed the entire test meals. Differences for glucose and insulin at single time points are shown in Fig. 1a, b.

Body weight gain only in younger adult mice on high-vs low-GI diets Body weight at baseline was significantly lower in the young-adult vs aged mouse cohorts $(p<0.001)$, as expected. The influence of the diet on the time course of increases in body weight was significant in young-adult ( $p<0.001$; Fig. $2 \mathrm{a})$, but not in aged mice ( $p=0.12$; Fig. $2 \mathrm{~b})$. In both young and aged animals the $\mathrm{Gipr}^{-1-}$ genotype had no significant effect on changes in body weight $(p>0.55)$. When comparing the 20 week intervention period of young-adult mice with the first 20 week period in aged animals the interaction of time $\times$ diet $\times$ age showed a significant influence $(p<0.001)$. However, differences in body weight between groups in aged mice did not reach the significance level, although we extended the intervention period in aged animals by a further 6 weeks (26 vs 20 weeks, compared with the younger mouse cohort). Therefore, the significant influence of the high-GI diet on body weight appeared to be age-dependent.

Increased body fat and hepatic triacylglycerol content on high-GI diet The diet significantly influenced changes in body fat both in young-adult mice after 9 and 16 weeks (two-way ANOVA, $p<0.001$; Fig. 2c) and in aged mice after 8 and 24 weeks $(p<0.05$; Fig. 2e) of dietary intervention. However, in subgroup analyses, significant differences in body fat between groups were only detected in young-adult mice (wild-type, high- vs low-GI diet, after 9 and 16 weeks, $p<0.01$; Gipr $^{-/-}$, high- vs low-GI diet, after 9 and 16 weeks, $p<0.05$ ), but not in aged mice (Fig. 2e, $p>0.05$, respectively). There was no effect of the Gipr genotype on body fat in young-adult and in aged mice 
a

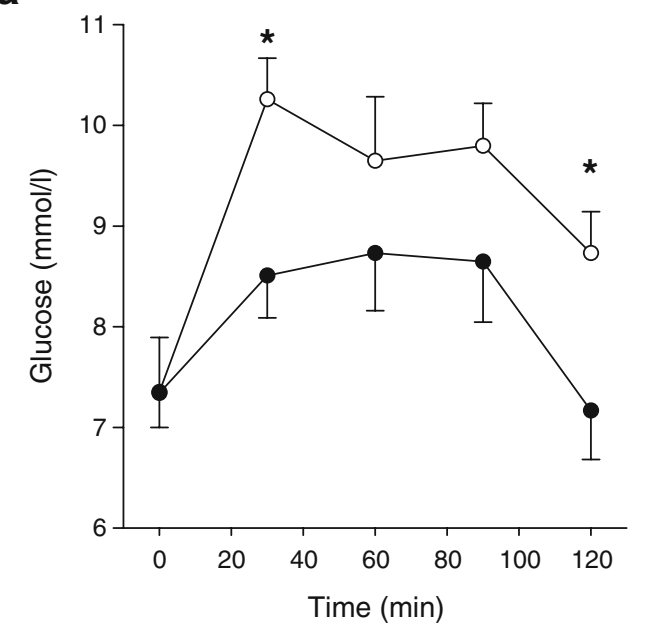

b

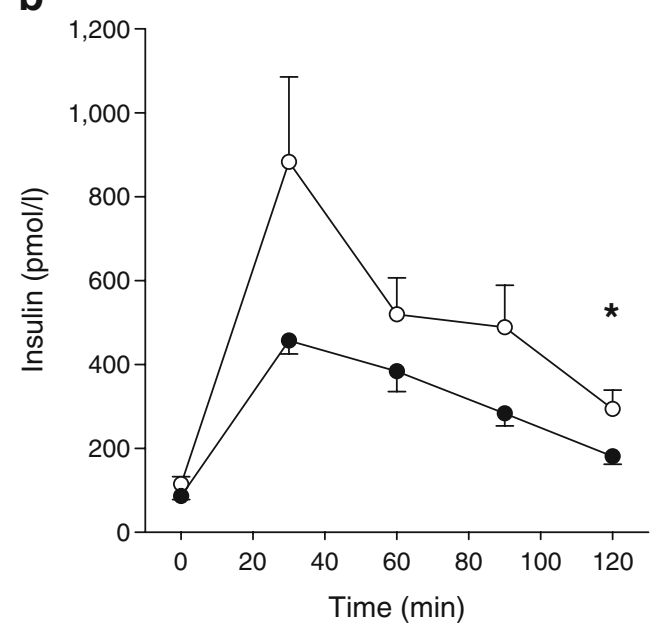

Fig. 1 Characterisation of the experimental diets. Plasma glucose (a) and insulin levels (b) after ingestion of $500 \mathrm{mg}$ of experimental diets with high-GI (white circles) and low-GI (black circles) diets. Means \pm SE. ${ }^{*} p<0.05, n=6$ per group

( $p=0.69$ and $p=0.26$, respectively). Relative changes in body fat showed similar results, with a significant effect of the diet at week 16 in young-adult $(p<0.001)$ and week 24 in aged $(p=0.013)$ mice. Two-way ANOVA analysis of lean mass alteration in young wild-type mice on high- and lowGI and $\mathrm{Fipr}^{-/-}$on high- and low-GI diets $(21.1 \pm 0.3,21.0 \pm$ $0.3,21.2 \pm 0.3$ and $21.1 \pm 0.3 \mathrm{~g}$ ) was influenced neither by the genotype $(p=0.81)$ nor by diet $(p=0.92)$ nor diet $\times$ genotype interaction $(p=0.98)$ after 16 weeks. There was also no influence of these three factors in aged mice after 24 weeks $(21.5 \pm 0.5,20.8 \pm 0.2,20.6 \pm 0.3$ and $21.5 \pm 0.4 \mathrm{~g}$, with $p=0.81, p=0.731$ and $p=0.08$, respectively).

In agreement with in vivo body fat nuclear magnetic resonance analysis, hepatic triacylglycerol content was significantly increased in both young (Fig. $2 \mathrm{~d}, p<0.001$ ) and aged animals (Fig. 2f, $p=0.02$ ) fed the high-GI diet, with no influence of the $\mathrm{Gipr}^{-1-}$ genotype $(p>0.46)$.
Higher energy digestion with high- vs low-GI diets, regardless of age and Gipr genotype Digestibility of diets (\%) was significantly elevated in high- vs low-GI fed wildtype animals, in both younger ( $95.3 \pm 0.2$ vs $90.8 \pm 0.4, p<$ $0.001)$ and aged $(94.7 \pm 0.3$ vs $89.5 \pm 0.9, p<0.001)$ mice. Similar differences were observed in younger $(95.2 \pm 0.3$ vs $90.1 \pm 0.4, p<0.001)$ and aged $(94.8 \pm 0.6$ vs $90.8 \pm 0.5, p<$ 0.001) $\mathrm{Gipr}^{-1-}$ mice. There was no difference in energy digestion between younger and aged mice.

$\mathrm{Gipr}^{-1}$ prevents an increase in cumulative energy intake on high-GI diet in aged animals In young-adult mice, cumulative net energy intake measured by recording of food intake over 18 weeks was not significantly different between groups, regardless of the diet and the Gipr genotype (Fig. 2g). In aged mice, however, cumulative net energy intake was significantly influenced by the diet after $11(p=0.006)$ and 22 weeks $(p=0.015)$, with a significant interaction of genotype $\times$ diet $(p=0.031)$ after 22 weeks, indicating an increased cumulative net energy intake on high-GI diet only in wild-type aged mice (Fig. 2h).

Improved estimated insulin sensitivity in aged $\mathrm{Gipr}^{-/}$mice on high-GI diet The response to i.p insulin injection was tested in all groups of mice after 17 weeks of dietary intervention. No differences in estimated insulin sensitivity were observed in young-adult mice using this method (Fig. 3a), despite the observed diet-induced significant differences in body fat. In aged animals, there was also no difference between Gipr genotypes on low-GI diet (Fig. 3b). However, the observed significant influence of the genotype $(p=0.014)$ and the interaction of genotype $\times$ diet $(p=0.0019)$ in $\mathrm{AUC}_{\text {glucose }}$ analysis (plasma glucose suppression by i.p. insulin injection) indicated a protective effect of GIPR deficiency in aged animals on a high-GI diet.

Two-way ANOVA analysis of changes in HOMA-IR in wild-type mice on high- and low-GI diets $(7.2 \pm 2.0$ vs $5.0 \pm$ 1.4) and in $\mathrm{Gipr}^{-1-}$ mice on high- and low-GI diets (3.0土 0.8 vs $3.5 \pm 0.6)$ supported a significant influence of the genotype $(p=0.035)$ in aged but not in young-adult animals $(6.9 \pm 1.3$ vs $4.7 \pm 1.7$, and $3.5 \pm 1.0$ vs $3.5 \pm 0.8, p=0.1)$, whereas diet and the interaction of diet $\times$ genotype did not reach a significant level, either in young-adult $(p>0.39)$ or in aged mice $(p>0.29)$.

GTTs were additionally performed and used as a further marker for the investigation of insulin resistance. While glucose excursions in young mice were mainly influenced by the high-GI diet $(p=0.004)$, independently of the $\mathrm{Gipr}^{-/-}$ genotype, in aged mice there was a significantly reduced AUC $_{\text {glucose }}$ in high-GI fed $\mathrm{Gipr}^{-1-}$ vs wild-type animals ( $p=$ 0.003). These findings were in accord with the results received after i.p. insulin injection, although the interaction 
Fig. 2 Body composition and energy intake. There was a significant interaction of diet $x$ time on body weight in youngadult (two-way ANOVA, $p<0.001$ ) (a), but not in aged mice $(p=0.12)(\mathbf{b})$. White circles: wild-type, high GI; black circles: wild-type, low GI; white triangles: $\mathrm{Gipr}^{-1}$, high GI; black triangles $\mathrm{Gipr}^{-1-}$, low GI. There was a significant effect of the diet on fat mass in young animals after 9 and 16 weeks $(p<0.001)(\mathbf{c})$, which was also significant $(p<0.05)$, but attenuated in aged animals after 8 and 24 weeks (e). Dietinduced changes in hepatic triacylglycerol contents are shown in young mice (d) $(p<0.001)$ and in aged mice (f) $(p=0.02)$ (data were normalised to the wild-type group with high-GI diet and set as 1.0). Cumulative energy intake was comparable in young animals (g), but significantly influenced by the diet in aged animals (h) $(p<0.01$ and $p<0.05$, respectively, after 11 and 22 weeks of dietary intervention), with a significant diet $\times$ genotype interaction after 22 weeks $(p<0.05)$. White bars: wild-type, high GI; grey bars: wild-type, low GI; white hatched bars: $\mathrm{Gipr}^{-1-}$, high GI; grey hatched bars: $\mathrm{Gipr}^{-1-}$, low GI. Means \pm SE. $* p<0.05$, $* * p<0.01$ in $t$ test subgroup analyses. $n=8-10$ per group

\section{a}

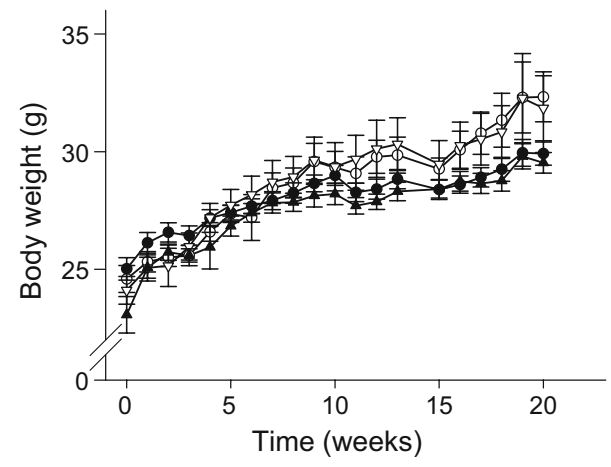

C
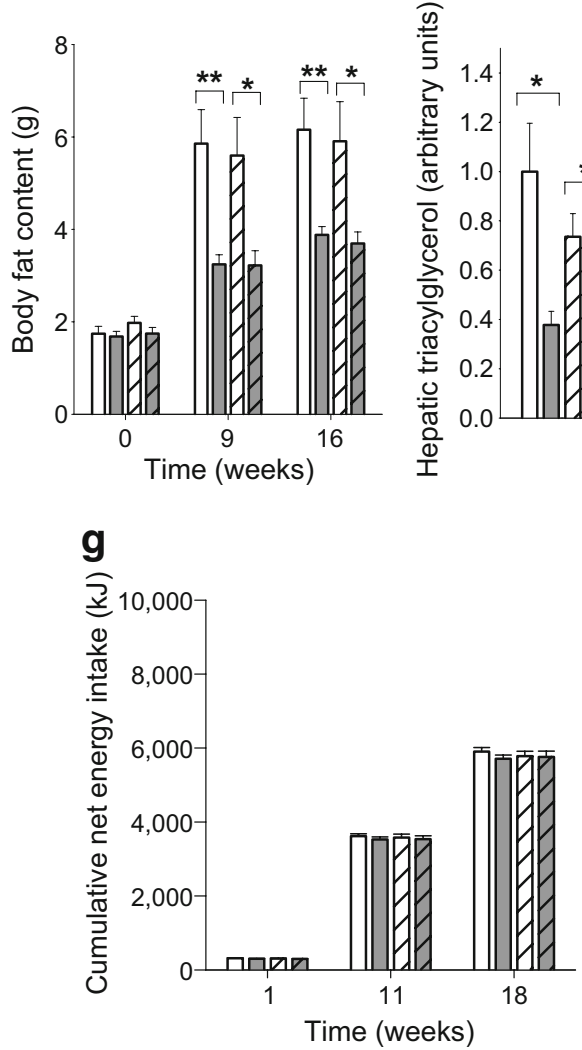

b

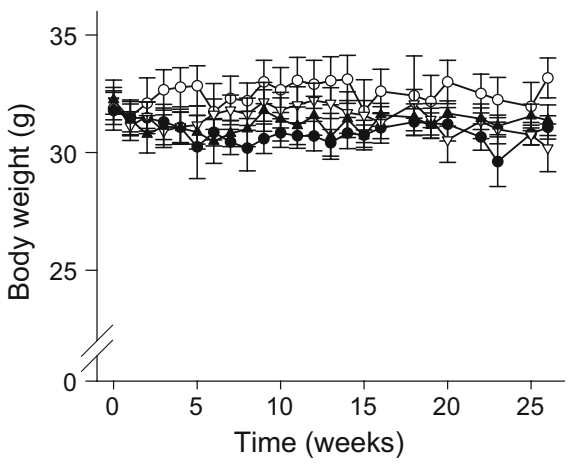

e
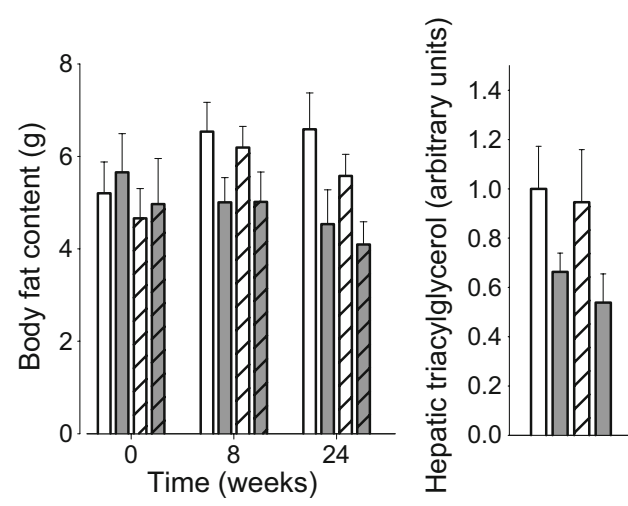

h

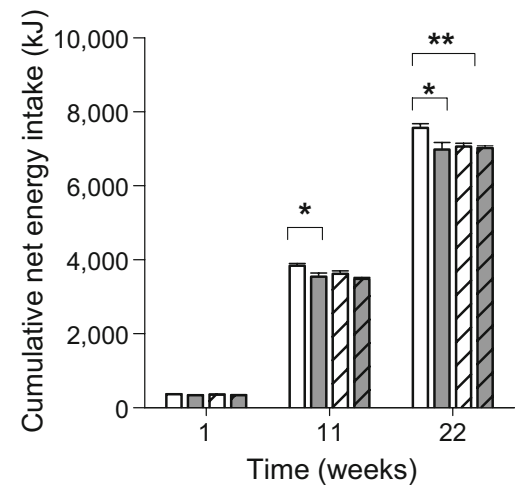

of the Gipr genotype with the diet failed to reach the level of significance $(p=0.26) . \mathrm{AUC}_{\text {insulin }}$ following i.p. glucose injection was not different on high- vs low-GI diet in all groups of mice (data not shown).

Improved carbohydrate oxidation in aged $\mathrm{Gipr}^{--}$mice on high-GI diet Results from indirect calorimetry further indicated an influence of dietary GI on metabolism in aged $\mathrm{Gipr}^{-/}$animals. The RQ in aged high- vs low-GI fed $\mathrm{Gipr}^{-/-}$mice was significantly higher during the dark phase, where most of the dietary intake takes place (Fig. 3f), indicating improved carbohydrate metabolism. This result was in agreement with the observed shift to improved insulin sensitivity. In contrast, the mirrored pattern of RQ, as observed in younger $\mathrm{Gipr}^{-1-}$ mice, suggested an improved rather than reduced carbohydrate metabolism on low-GI diet (Fig. 3e). Mean RQ showed no significant differences in high- vs low-GI fed wild-type animals, either in young-adult $(p=0.35)$ or in aged $(p=0.37)$ mice (data not shown). These data indicated that, in the GIPR-deficient state, the age of the animals contributed to diverse outcomes when assessing potential beneficial effects of low- vs high-GI diets.

Mean energy expenditure per metabolic mass in young wild-type mice on high- and low-GI and $\mathrm{Gipr}^{-1-}$ on highand low-GI diets $(750.8 \pm 0.4,703.6 \pm 18.2$ and $735.9 \pm 11.2$, 
Fig. 3 Markers of insulin sensitivity and substrate oxidation. Plasma glucose levels after i.p. insulin injection after 17 weeks of dietary intervention in young-adult (a) and aged (c) mice. There was a significant influence of the genotype (twoway ANOVA, $p<0.05$ ) and a genotype $\times$ diet interaction $(p<0.05)$ in aged, but not in young mice. AUCs for young (b) and aged animals (d) are presented: white bars: wild-type, high GI; grey bars: wild-type, low GI; white hatched bars: $\mathrm{Gipr}^{-/-}$, high GI; grey hatched bars: $\mathrm{Gipr}^{-1-}$, low GI. Glucose levels after i.p. glucose injection after 15 weeks of intervention in young (e) and after 20 weeks in aged mice (g) with

corresponding AUCs (f and $\mathbf{h}$, respectively). There was a significant influence of diet only in young mice $(p<0.05)$, whereas in aged mice a significant influence of the genotype was detected $(p<0.01)$. RQ in young-adult (after 12 weeks of dietary intervention) (i) and aged $\mathrm{Gipr}^{-1-}$ (after 20 weeks of dietary intervention) (j) mice on high- vs low-GI diets. Dark phase was 18:00 hours to 06:00 hours. RQ in aged mice was significantly increased (j), indicating improved carbohydrate metabolism on high-GI diet. A mirrored pattern of RQ was observed in younger animals

(i). White circles: wild-type, high GI; black circles: wildtype, low GI; white triangles: $\mathrm{Gipr}^{-1-}$, high GI; black triangles: Gipr $^{-\top}$, low GI. Means \pm SE. ${ }^{*} p<0.05,{ }^{* *} p<0.01$ in $t$ test subgroup analyses, $n=8-10$ per group
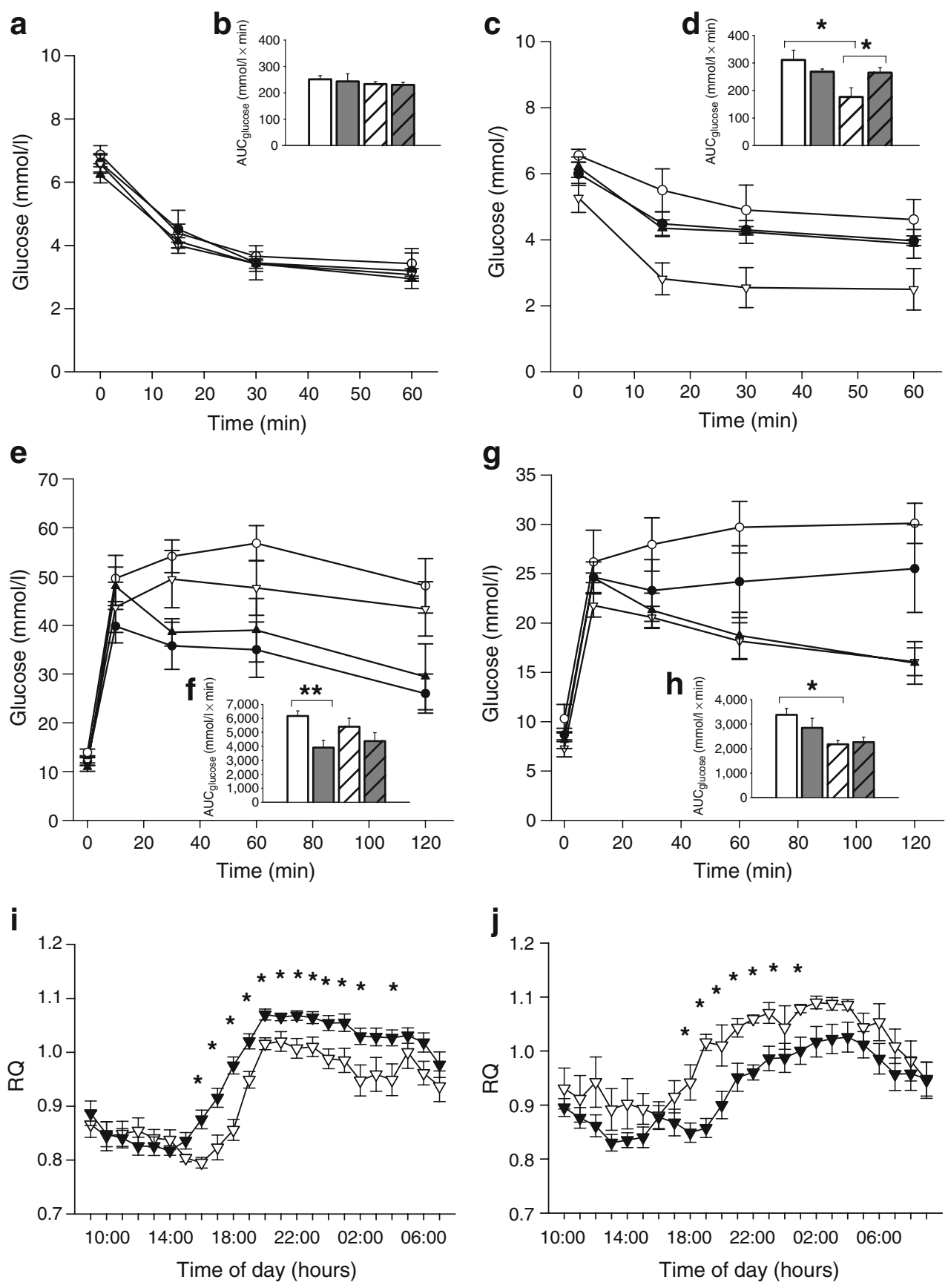

$\left.716.2 \pm 22.5 \mathrm{~kJ} \mathrm{day}^{-1} \mathrm{~kg}^{-0.75}\right)$ was not influenced by genotype $(p=0.95)$, diet $(p=0.08)$ or diet $\times$ genotype interaction $(p=$ $0.47)$ in two-way ANOVA analysis. There was also no influence of these three factors in aged animals ( $574.3 \pm 12.3$, $583.9 \pm 24.7$ and $592.0 \pm 16.0,602.5 \pm 9.5 \mathrm{~kJ} \mathrm{day}^{-1} \mathrm{~kg}^{-0.75}$, with $p=0.279, p=0.54$ and $p=0.98$, respectively).

Increased locomotor activity in aged $\mathrm{Gipr}^{-/}$mice on highGI diet Given that a significant difference in estimated insulin sensitivity was detected in aged high-GI fed $\mathrm{Gipr}^{-/-}$ vs wild-type mice despite unaltered body weight after 24 weeks of dietary intervention, we hypothesised that potential changes in locomotor activity could have contributed to the observed findings. Therefore, spontaneous locomotor activity was recorded in aged mice after 24 weeks of dietary intervention (Fig. 4).

Spontaneous locomotor activity during the dark phase, where most of the natural activity takes place in rodents, showed a significant influence of the genotype (two-way ANOVA, $p<0.05)$ and a trend in interaction of diet $\times$ genotype $(p=0.09)$, indicating increased activity levels in the high-GI fed $\mathrm{Gipr}^{-/-}$vs wild-type animals. No differences between groups were observed during the light phase (Fig. 4). 


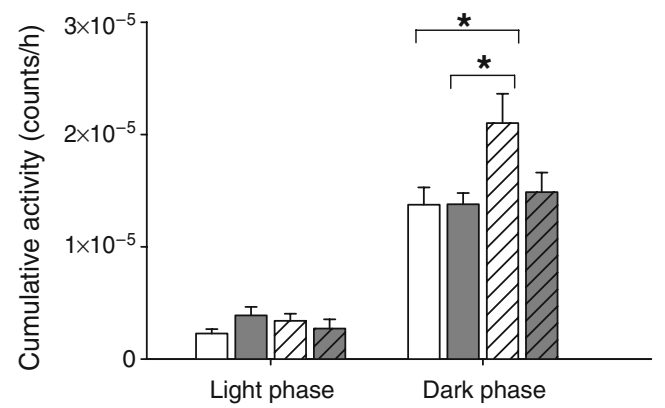

Fig. 4 Spontaneous locomotor activity in aged mice, measured during the light phase and the dark phase over a $24 \mathrm{~h}$ period, after 25 weeks of intervention with high- vs low-GI diets. There was a significant influence of the genotype (two-way ANOVA, $p<0.05$ ). White bars: wild-type, high GI; grey bars: wild-type, low GI; white hatched bars: $\mathrm{Gipr}^{-1-}$, high GI; grey hatched bars: $\mathrm{Gipr}^{-1-}$, low GI. Means $\pm \mathrm{SE}$. ${ }^{*} p<0.05$ in $t$ test subgroup analyses, $n=8$ per group

Changes in hypothalamic orexigenic and anorexigenic factors in aged mice Two-way ANOVA analysis of mRNA expression of hypothalamic factors related to energy intake revealed a significant genotype $\times$ diet interaction in aged mice for Agrp transcription $(p=0.022)$, and an influence of the diet on Pomc transcription $(p<0.046)$. Npy and Cart were not significantly influenced by either factor (Fig. 5). Unexpectedly, the anorexigenic factor genes Pomc and Cart in both high-GI fed wild-type and Gipr $^{-1-}$ animals even tended to increase, probably representing a compensatory mechanism. The orexigenic Agrp tended to decrease only in $\mathrm{Gipr}^{-1-}$ mice on low-GI diet (subgroup analysis, Fig. 5), while Npy showed no obvious tendencies between groups.

\section{Discussion}

Nutrition strongly modulates risk factors in the development of obesity and metabolic disorders [26]. High- vs lowGI diets increase body fat mass and insulin resistance in rodents [1, 2, 13-17], and have also been proposed to be potentially harmful in humans [27, 28]. Nevertheless, although there are numerous preclinical reports assessing the effect of diets on body weight, benefits of low-GI diets have not been consistently shown in clinical studies [6, 2933]. We hypothesised that controversial results from human studies might be explained, in part, by differences in age of the investigated individuals, as indicated by findings from prospective cohort studies [3, 12]. Furthermore, apart from dietary fat, dietary carbohydrates are the main physiological stimulators of GIP secretion [34, 35]. Therefore, diets varying in carbohydrate absorption and, as such, GI, could have diverse effects in wild-type vs GIPR-deficient states, thereby modulating insulin secretion, fat metabolism and locomotor activity [19, 20, 34, 35].
Herein, we present novel findings showing that a highvs low-GI diet significantly increased body weight in young-adult, but not in aged mice, regardless of the Gipr genotype. Increased fat mass in younger wild-type animals on long-term high- vs low-GI diets was further observed, which is in agreement with a recently published study [2] reporting significantly increased body fat in $129 \mathrm{ScPas}$ mice fed a high-GI diet from a young age and with most of the diet-induced differences in body fat being apparent as early as 10-12 weeks after the intervention had started. Importantly, when beginning the high-GI intervention in aged animals, as performed in the present study, no diet-induced differences in body weight were observed. Furthermore, diet-induced differences in fat mass were less pronounced in aged animals, even after extending the dietary intervention by a further 6 weeks. These data indicate that low- vs high-GI diets appeared to have more pronounced effects on body weight and fat mass in young-adult vs aged animals in the present study.

Results from glucose tolerance tests indicated that carbohydrate metabolism in young-adult animals on the high-GI diet was indeed reduced. These changes were independent of the Gipr genotype in young-adult animals, whereas the Gipr genotype appeared to be the driving factor for alterations in carbohydrate metabolism in high-GI fed aged mice. Interestingly, aged high-GI fed $\mathrm{Gipr}^{-1-}$ showed significantly improved insulin sensitivity, which was probably caused by the combination of lower cumulative

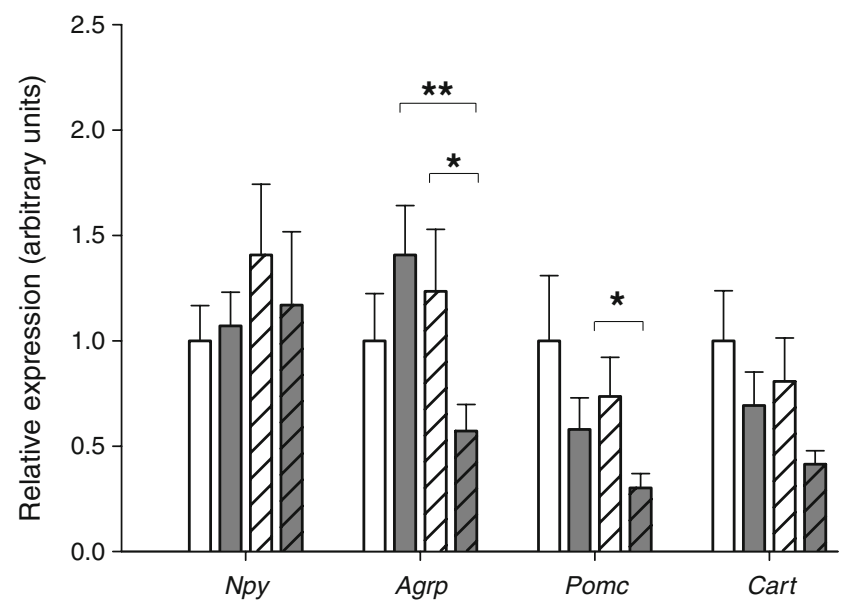

Fig. 5 Changes in orexigenic and anorexigenic hypothalamic factors. Real-time RT-PCR analysis of orexigenic and anorexigenic factor genes in the hypothalamus of aged mice. Results were normalised to the internal control, and the wild-type group with high-GI diet was set as 1.0. There was a significant genotype $\times$ diet interaction on changes in Agrp transcription (two-way ANOVA, $p<0.05$ ), and a diet effect on Pomc transcription $(p<0.05)$. Npy and Cart were unaffected by either factor. White bars: wild-type, high GI; grey bars: wild-type, low GI; white hatched bars: $\mathrm{Gipr}^{-/-}$, high GI; grey hatched bars: Gipr ${ }^{--}$, low GI. Means \pm SE. ${ }^{*} p<0.05,{ }^{*} p<0.01$ in $t$ test subgroup analysis, $n=$ 8 per group 
net energy intake and significantly increased locomotor activity.

To the best of our knowledge, this is the first report showing the effect of a high-GI diet on the expression of hypothalamic neuropeptide genes. Previous reports have suggested that the rapid absorption of glucose after consumption of high-GI meals induces a sequence of hormonal and metabolic changes that promote excessive food intake in obese individuals [36]. The increased transcription levels of the orexigenic neuropeptide Agrp gene in the $\mathrm{Gipr}^{-/-}$animals on high- vs low-GI diet may explain an acute stimulation of food intake. However, the total cumulative food intake was unchanged between $\mathrm{Gipr}^{-/-}$mice, probably explained by the compensatory effects of upregulated anorexigenic Pomc expression. Unexpectedly, the expression of the studied neuropeptides did not significantly change between wild-type and $\mathrm{Gipr}^{-/-}$ mice fed high-GI diet, even though the cumulative food intake was higher in wild-type mice. Therefore, analysis of expression of hypothalamic factors in specific hypothalamic nuclei, as well as the investigation of food reward mechanisms could be useful in future studies.

The exact mechanisms of how chronic consumption of high-GI diets leads to fat accumulation are still under debate. One important factor might be the high-GI dietinduced postprandial hyperinsulinaemia. Furthermore, in former studies in rats, enhanced insulin-stimulated glucose oxidation and glucose incorporation into total lipids with increased fat pads were observed [14]. Therefore, dietinduced increases of insulin levels might alter nutritional partitioning in favour of fat deposition, e.g. by shunting metabolic fuels from oxidation in muscle to storage in fat [36]. Moreover, enhanced de novo lipogenesis, which also leads to an increased hepatic triacylglycerol accumulation, directly inhibits fatty acid oxidation [37, 38]. This ongoing circle may induce an increase in body weight and fat accumulation in the long-term, although less pronounced detrimental effects in aged animals remain to be explained.

Age-associated accumulation of visceral fat is strongly associated with metabolic disturbances, including insulin resistance in humans $[23,39,40]$. In order to recommend the most suitable and effective diets to our patients, it appears to be important to investigate whether agedependent differences between low- vs high-GI diets also exist in humans. Considering the reported smaller effects of diets differing in GI in patients of advanced age [12], wellcontrolled intervention studies in aged humans are recommended to justify the considerable efforts of complying with a low-GI diet. The present study was based on a highcarbohydrate and low-fat diet, as usually performed in rodent GI studies [18]. However, a typical Western style diet is also high in dietary fat. Therefore, as also indicated by recent results from others [18], varying the carbohydrate vs fat content in future clinical studies investigating effects of high- vs low-GI diets appears to be relevant.

In conclusion, low- vs high-GI diets beneficially affected body weight and metabolic markers in younger mice, regardless of the Gipr genotype, whereas no obvious advantage of a low-GI diet could be observed in aged wild-type animals. Blockade of GIP action in aged animals on a high-GI diet, however, significantly improved estimates of insulin sensitivity, indicating that selective pharmacological blockage of GIP action in aged humans consuming high-GI diets could be beneficial.

Acknowledgements F. Isken and A. F. Pfeiffer were supported by a grant of the Deutsche Forschungs Gesellschaft (DFG, PF 164/14-1). M. O. Weickert was supported by a grant of the German Ministry of Education and Science (BMBF, 0313826A). We thank S. Richter, K. Weinert, C. Plaue and K. Wagner for excellent technical assistance.

Duality of interest The authors declare that there is no duality of interest associated with this manuscript.

\section{References}

1. Pawlak DB, Kushner JA, Ludwig DS (2004) Effects of dietary glycaemic index on adiposity, glucose homoeostasis, and plasma lipids in animals. Lancet 364:778-785

2. Scribner KB, Pawlak DB, Aubin CM, Majzoub JA, Ludwig DS (2008) Long-term effects of dietary glycemic index on adiposity, energy metabolism, and physical activity in mice. Am J Physiol Endocrinol Metab 295:E1126-E1131

3. Barclay AW, Petocz P, McMillan-Price J et al (2008) Glycemic index, glycemic load, and chronic disease risk-a meta-analysis of observational studies. Am J Clin Nutr 87:627-637

4. Diaz EO, Galgani JE, Aguirre CA (2006) Glycaemic index effects on fuel partitioning in humans. Obes Rev 7:219-226

5. Kelly S, Frost G, Whittaker V, Summerbell C (2004) Low glycaemic index diets for coronary heart disease. Cochrane Database Syst Rev, Issue 4, Art no.:CD004467. doi:10.1002/ 14651858.CD004467.pub2

6. Pi-Sunyer X (2005) Do glycemic index, glycemic load, and fiber play a role in insulin sensitivity, disposition index, and type 2 diabetes? Diabetes Care 28:2978-2979

7. Thomas DE, Elliott EJ, Baur L (2007) Low glycaemic index or low glycaemic load diets for overweight and obesity. Cochrane Database Syst Rev, Issue 3, Art no.:CD005105. doi:10.1002/ 14651858.CD005105.pub2

8. Weickert MO, Pfeiffer AF (2008) Metabolic effects of dietary fiber consumption and prevention of diabetes. J Nutr 138:439-442

9. Liu S, Willett WC, Stampfer MJ et al (2000) A prospective study of dietary glycemic load, carbohydrate intake, and risk of coronary heart disease in US women. Am J Clin Nutr 71:1455-1461

10. Schulze MB, Liu S, Rimm EB, Manson JE, Willett WC, Hu FB (2004) Glycemic index, glycemic load, and dietary fiber intake and incidence of type 2 diabetes in younger and middle-aged women. Am J Clin Nutr 80:348-356

11. Zhang C, Liu S, Solomon CG, Hu FB (2006) Dietary fiber intake, dietary glycemic load, and the risk for gestational diabetes mellitus. Diabetes Care 29:2223-2230

12. van Dam RM, Visscher AW, Feskens EJ, Verhoef P, Kromhout D (2000) Dietary glycemic index in relation to metabolic risk factors 
and incidence of coronary heart disease: the Zutphen Elderly Study. Eur J Clin Nutr 54:726-731

13. Byrnes SE, Miller JC, Denyer GS (1995) Amylopectin starch promotes the development of insulin resistance in rats. J Nutr 125:1430-1437

14. Kabir M, Rizkalla SW, Champ M et al (1998) Dietary amyloseamylopectin starch content affects glucose and lipid metabolism in adipocytes of normal and diabetic rats. J Nutr 128:35-43

15. Lerer-Metzger M, Rizkalla SW, Luo J et al (1996) Effects of longterm low-glycaemic index starchy food on plasma glucose and lipid concentrations and adipose tissue cellularity in normal and diabetic rats. Br J Nutr 75:723-732

16. Pawlak DB, Bryson JM, Denyer GS, Brand-Miller JC (2001) High glycemic index starch promotes hypersecretion of insulin and higher body fat in rats without affecting insulin sensitivity. J Nutr 131:99-104

17. Scribner KB, Pawlak DB, Ludwig DS (2007) Hepatic steatosis and increased adiposity in mice consuming rapidly vs slowly absorbed carbohydrate. Obesity (Silver Spring) 15:2190-2199

18. van Schothorst EM, Bunschoten A, Schrauwen P, Mensink RP, Keijer J (2009) Effects of a high-fat, low- vs high-glycemic index diet: retardation of insulin resistance involves adipose tissue modulation. FASEB J 23:1092-1101

19. Miyawaki K, Yamada Y, Ban N et al (2002) Inhibition of gastric inhibitory polypeptide signaling prevents obesity. Nat Med 8:738742

20. Ding KH, Zhong Q, Xie D et al (2006) Effects of glucose-dependent insulinotropic peptide on behavior. Peptides 27:2750-2755

21. Isken F, Pfeiffer AF, Nogueiras R et al (2008) Deficiency of glucose-dependent insulinotropic polypeptide receptor prevents ovariectomy-induced obesity in mice. Am J Physiol Endocrinol Metab 295:E350-E355

22. Gatenby SJ, Ellis PR, Morgan LM, Judd PA (1996) Effect of partially depolymerized guar gum on acute metabolic variables in patients with non-insulin-dependent diabetes. Diabet Med 13:358-364

23. Yamada C, Yamada Y, Tsukiyama K et al (2007) Genetic inactivation of GIP signaling reverses aging-associated insulin resistance through body composition changes. Biochem Biophys Res Commun 364:175-180

24. Preitner F, Ibberson M, Franklin I et al (2004) Gluco-incretins control insulin secretion at multiple levels as revealed in mice lacking GLP-1 and GIP receptors. J Clin Invest 113:635-645

25. Isken F, Schulz TJ, Möhlig M, Pfeiffer AF, Ristow M (2006) Chemical inhibition of citrate metabolism alters glucose metabolism in mice. Horm Metab Res 38:543-545

26. Feige JN, Lagouge M, Auwerx J (2008) Dietary manipulation of mouse metabolism. Curr Protoc Mol Biol Chapter 29: Unit 29B.25
27. Brand-Miller J, McMillan-Price J, Steinbeck K, Caterson I (2008) Carbohydrates - the good, the bad and the whole grain. Asia Pac J Clin Nutr 17(Suppl 1):16-19

28. Josse AR, Panahi S, Esfahani A, Leiter LA, Jenkins DJ, Kendall CW (2008) Nutritional considerations for older adults with type 2 diabetes. J Nutr Elder 27:363-380

29. Marshall JA, Bessesen DH, Hamman RF (1997) High saturated fat and low starch and fibre are associated with hyperinsulinaemia in a non-diabetic population: the San Luis Valley Diabetes Study. Diabetologia 40:430-438

30. Meyer KA, Kushi LH, Jacobs DR Jr, Slavin J, Sellers TA, Folsom AR (2000) Carbohydrates, dietary fiber, and incident type 2 diabetes in older women. Am J Clin Nutr 71:921-930

31. Salmeron J, Ascherio A, Rimm EB et al (1997) Dietary fiber, glycemic load, and risk of NIDDM in men. Diabetes Care 20:545-550

32. Salmeron J, Manson JE, Stampfer MJ, Colditz GA, Wing AL, Willett WC (1997) Dietary fiber, glycemic load, and risk of noninsulin-dependent diabetes mellitus in women. JAMA 277:472477

33. Stevens J, Ahn K, Juhaeri HD, Steffan L, Couper D (2002) Dietary fiber intake and glycemic index and incidence of diabetes in African-American and white adults: the ARIC study. Diabetes Care 25:1715-1721

34. Holst JJ, Vilsboll T, Deacon CF (2009) The incretin system and its role in type 2 diabetes mellitus. Mol Cell Endocrinol 297:127-136

35. Meier JJ, Nauck MA (2004) Clinical endocrinology and metabolism. Glucose-dependent insulinotropic polypeptide/gastric inhibitory polypeptide. Best Pract Res Clin Endocrinol Metab 18:587-606

36. Ludwig DS, Majzoub JA, Al-Zahrani A, Dallal GE, Blanco I, Roberts SB (1999) High glycemic index foods, overeating, and obesity. Pediatrics 103:E26. doi:10.1542/peds.103.3.e26 Available from www.pediatrics.org/cgi/content/full/103/3/e26, accessed 3 July 2009

37. Foster DW (2004) The role of the carnitine system in human metabolism. Ann N Y Acad Sci 1033:1-16

38. Hellerstein MK, Schwarz JM, Neese RA (1996) Regulation of hepatic de novo lipogenesis in humans. Annu Rev Nutr 16:523557

39. Coon PJ, Rogus EM, Drinkwater D, Muller DC, Goldberg AP (1992) Role of body fat distribution in the decline in insulin sensitivity and glucose tolerance with age. J Clin Endocrinol Metab 75:1125-1132

40. Kohrt WM, Kirwan JP, Staten MA, Bourey RE, King DS, Holloszy JO (1993) Insulin resistance in aging is related to abdominal obesity. Diabetes 42:273-281 